\title{
A refined numerical simulation on dynamic behavior of roller chain drives
}

\author{
H. Zheng ${ }^{\mathrm{a}, *}$, Y.Y. Wang ${ }^{\mathrm{a}}$ and K.P. Quek ${ }^{\mathrm{b}}$ \\ anstitute of High Performance Computing, 1 Science Park Road, \#01-01 The Capricorn, Science Park II, \\ Singapore 117528 \\ bunstar Engineering Inc., Kusatsu, Shiga 525, Japan
}

Received 18 July 2001

Revised 1 January 2004

\begin{abstract}
A refined numerical analysis of the dynamic behavior of roller chain drives is performed considering the roller assembly as a three-layer structure with mechanical clearance between each two of the mechanical components. Instead of using analytical method, explicit finite element technique is utilized for modeling and simulating the dynamic behavior of chain drives. The complete standard geometry of sprockets and all components of chain links are used in the developed model with minor geometry simplification. A primary goal is to achieve a more complete understanding of the dynamic behavior of chain drives especially in the transient vibration response of the engaging rollers, which is crucial for noise emission calculation. The simulated velocity response of the engaging rollers and roller-sprocket contact forces achieved using the full model are compared with what found by the simple model which has been adopted in analytical study of chain roller dynamics.
\end{abstract}

\section{Introduction}

Owing to the discrete nature of the roller chain and non-trivial geometry of the sprocket teeth, chain drives behave dynamically in a very complex manner. The discrete nature brings chain drives disadvantages of noise and vibration with which the designers have been concerned. The undesirable noise and vibration characteristics have motivated researchers to investigate the dynamic behavior of designed chain drives for various engineering purposes.

The literature concerning the dynamic behavior of chain drives is very extensive. Four major categories on the topic may be classified. They are, 1) load distribution analysis, 2) kinematics analysis, 3) transverse and longitudinal vibration analyses of the chain span, and 4) analysis of impact intensity between the engaging roller and the sprocket.

Naji and Marshek [1] made an analysis to determine the load distribution of the elastic roller chain on an elastic sprocket. An experimental study was also conducted to determine the effect of elastic properties, geometric variations, and lubrication on roller chain load distributions [2]. Conwell and Johson [3] designed a unique machine capable of measuring the bearing force of a sprocket and the strain of the moving chain at the mid-point of a chain link. Using this test machine, the effect of pre-load, transmitted load, and speed can be investigated [4].

The motion of the roller chain drive at low speeds has been studied using the kinematic model in which inertia is assumed to be zero and chain span behaves as a rigid bar connecting two polygons made by the sprockets [5, 6]. This kinematics analysis quantifies the polygonal action and its influence on the system. As the operating speed increases, the inertia effects of the roller chain drive become increasingly important. As such, during the chain/sprocket meshing process, the polygonal action and the impact between the chain and the sprocket teeth create excitation forces of the system vibration. This vibration may be resonant under certain operating conditions. Sack [7] studied the transverse oscillations in a travelling uniform string pulled over two smooth supports under

\footnotetext{
*Corresponding author. Tel.: +65 6419 1573; Fax: +65 6778 0522; E-mail: zhengh@ihpc.a-star.edu.sg.
} 
Table 1

Geometry of Sprockets

\begin{tabular}{lcc}
\hline Dimension $(\mathrm{mm})$ & Driving sprocket & Driven sprocket \\
\hline Outside diameter & 81.8 & 219.0 \\
Pitch diameter & 76.85 & 212.43 \\
Bottom diameter & 66.28 & 202.82 \\
Hub diameter & 33.0 & N.A. \\
Bore & 25.0 & N.A. \\
Pitch & & 15.875 \\
\hline
\end{tabular}

constant tension and speed. Mahalingam [8] used the same model as Sack but also included the centrifugal tension to analyze the resonance of roller chains due to polygonal motion. Research on the impact has been done on the effective mass [9,10], the contact stiffness [11], the elastic collision [12], and the intensity of impact interacting with transverse vibration [13-15]. Choi and Johson [16] completed the development of an axially moving material model that includes the effects of polygonal action and impact, and is also capable of incorporating a chain tensioner into the analysis. Veikos and Freudenstein [17] developed a dynamic model using the Langrange approach and accounting for the discrete nature and elasticity of the chain, the dependence of the boundary conditions on the motion, and the load inertia.

These theoretical analyses and associated numerical solutions provide designers with a good insight into those important characteristics of chain drives, such as the details of the engagement process, the trajectory of the roller chain, the impact between roller and sprocket teeth, and the vibration of the system. Particularly, the knowledge of surface vibration of chain rollers is crucial for effectively predicting the meshing noise from a chain drive system [18]. Due to the complexity of the problem, however, the chain strand has in nearly all of previous investigations been approximated as a series of point masses lumped at the roller centers that are connected together by massless bars of constant axial stiffness. All mechanical clearance, including those between pins and bushes, between bushes and rollers are also assumed to be negligible. These assumptions are necessary for theoretical modeling and analysis since the derivation of the chain equations of motion would be extremely complex should the chain link be considered as a multiple-component structure with relative motion and/or the connecting plates be modeled as non-uniform elastic bars or beams. Adopting these assumptions, it has been shown that the dynamic response is ideally identical for all engaging rollers under excitations of polygon action and roller/sprocket impacts. Furthermore, from these numerical solutions, it is difficult to see the difference in the roller/sprocket impact between roller-driving sprocket and roller-driven sprocket.

With the advances in computational mechanics techniques and in high performance computing resources, the difficulty encountered in the theoretical analysis of chain drives can be overcome by employing numerical modeling and simulation techniques. In this paper, the simulation of dynamic behavior of a roller chain drive is performed considering the mechanical clearance between each two of the mechanical components comprising the roller assembly, i.e., roller, bush and pin. These components are modeled as a three-layer structure with sliding contact with friction. Explicit finite element technique is utilized for modeling and simulating the dynamic behavior in time-domain. The complete standard geometry of sprockets and all components of chain links are used in the developed model with minor geometry simplification. A primary goal is to achieve a more complete understanding of the dynamic behavior of chain drives especially in the transient vibration response of the engaging rollers, and the contact force between engaging rollers and sprocket teeth. An attempt is made particularly to attain solutions of roller surface vibration with enough reliability for meshing noise calculation. The simulated velocity response of the engaging rollers and roller-sprocket contact forces achieved using the full model are compared with what found by the simple model which has been adopted in analytical study of chain roller dynamics.

\section{Finite element models of roller chain drive}

Modelling and dynamic analysis of any chain drive system of realistic complexity is not a simple task, even the efficient finite element analysis techniques are adopted to solve the problem. One of these complex systems usually involves at least two sprockets and a series of chain links. One assembly of the chain link further comprises side 

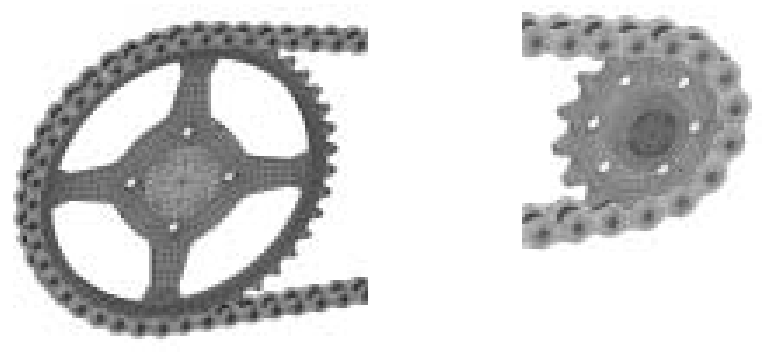

Fig. 1. Finite element mesh of the simulated chain drive.

Table 2

Dimension of the chain roller components

\begin{tabular}{lccc}
\hline Component & Inner diameter $(\mathrm{mm})$ & Outer diameter $(\mathrm{mm})$ & Cylinder length $(\mathrm{mm})$ \\
\hline Roller & 7.52 & 10.16 & 7.0 \\
Bushing & 5.33 & 7.43 & 9.94 \\
Pin & 2.68 & 5.24 & 14.94 \\
\hline
\end{tabular}

Table 3

Comparison of CPU times for solving simple and full models

\begin{tabular}{lccccc}
\hline & \multicolumn{2}{c}{ Simple model } & & \multicolumn{2}{c}{ Full model } \\
\cline { 2 - 3 } \cline { 5 - 6 } & CPU time $(\mathrm{s})$ & Percentage $(\%)$ & & CPU time (s) & Percentage (\%) \\
\hline Internal force & $2.373 \mathrm{E}+02$ & 4.35 & & $2.841 \mathrm{E}+05$ & 27.74 \\
Time integration & $2.847 \mathrm{E}+03$ & 52.81 & & $2.607 \mathrm{E}+05$ & 29.16 \\
Contact algorithm & $8.902 \mathrm{E}+02$ & 16.31 & & $3.297 \mathrm{E}+05$ & 36.67 \\
Total (including initiation time) & $5.457 \times 10^{3}$ & & & $8.941 \times 10^{5}$ & \\
\hline
\end{tabular}

plates, pins, bushes and rollers. Also the interaction between these components are nonlinear. In addition, loading and operational speed may impose additional complexities.

In order to achieve our target, two finite element models of a chain drive with difference in the modelling of chain links are developed. In a so-called "full-model", the complete standard geometry of sprockets and all components of chain links are used with minor geometry simplification. Figure 1 shows the finite element meshes of the model, which represents a chain drive for power transmission of motorcycles, for explicit finite element analysis of the system dynamic behaviour.

This chain drive comprises 110 chain link assemblies, a 15-tooth driving sprocket, and a 42-tooth driven sprocket. Both sprockets and all chain links are modelled in full geometrical details. 8-node brick elements are used to construct the finite element model of sprockets, rollers and bearing pins, while the link plates and bushes are meshed using 2D shell elements. The whole model consists of 78744 solid elements, 33440 shell elements, and 171245 nodes. Tables 1 and 2 list respectively the major geometry parameters of two sprockets and chain links of the model.

Owing to the symmetry of whole chain-sprocket system about its central plane, the side plates of the roller chain undergo only in-plane stresses. One integration point is therefore specified through the thickness of the shell elements. The number of the integration point is so specified that a membrane behavior is got for all the elements of side plates [19]. Also the computation time for solving the model can be significantly saved.

All the components except the central parts of sprockets are modelled as elastic bodies, while the central parts of sprockets that represent the shaft of sprocket are modelled as rigid bodies. The material used for all the components is carbon steel, and its physical parameters input in the model include Young's Modulus $E=210$ GPa, Poisson's Ratio $\nu=0.3$, and Mass Density $\rho=7600 \mathrm{~kg} / \mathrm{m}^{3}$.

A total of 274 contact interfaces are defined between all components potentially contacting with each other in the model such as among roller-bush, bush-pin, and particularly concerned, roller-sprocket to model the physical engagement. All these contact pairs are of frictional sliding. This type of contact interface, among the contact definitions available in current explicit FE codes, is most general one used where bodies come into contact but can separate again [19]. So it is particularly suitable for modeling the contacts between the rollers and sprockets, roller 


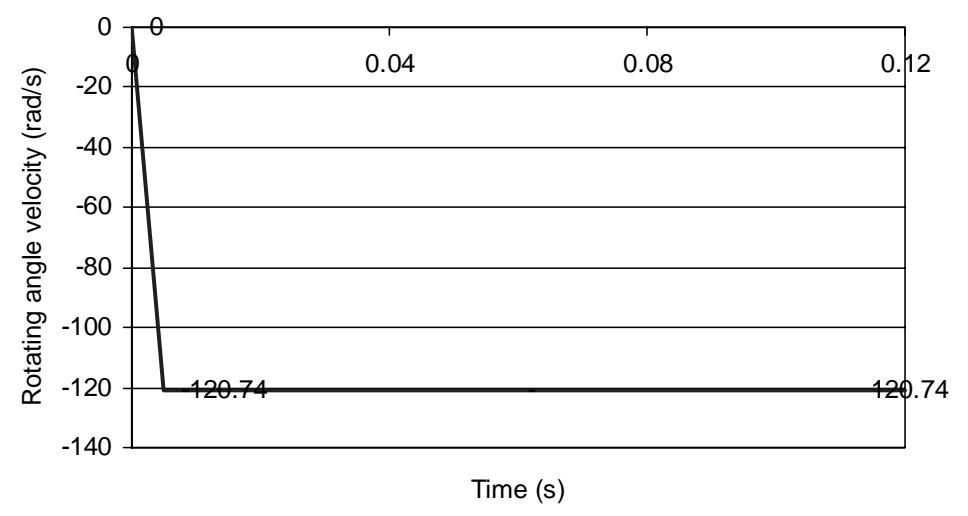

Fig. 2. Rotation-angular velocity imposed at the center of driving sprocket.

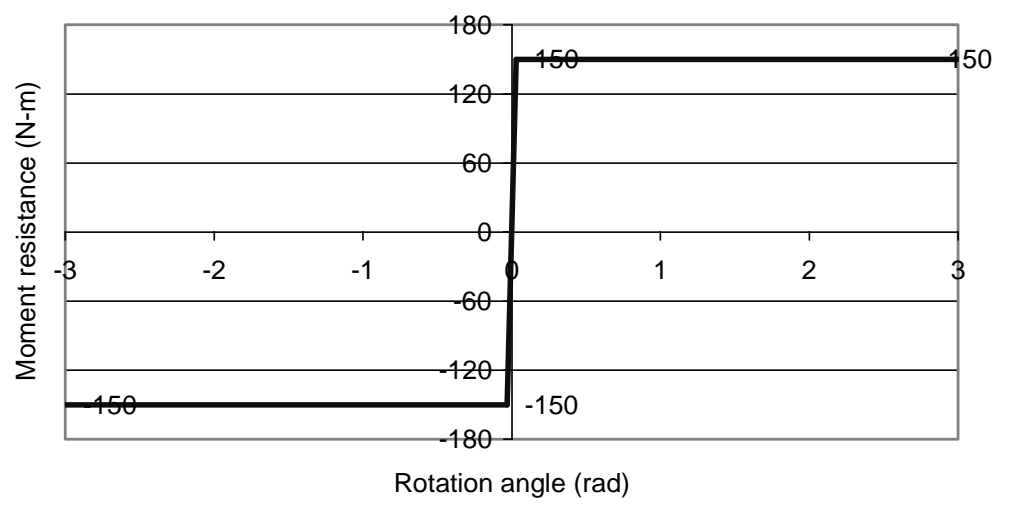

Fig. 3. Rotation-angular resisting torque imposed at the center of driven sprocket.

and corresponding bush, and bush and corresponding pin. No lubrication has been considered here. Penalty method, which guarantees conservation of momentum and kinetic energy, is adapted to surface-surface contact algorithm for possible penetration search. To take into account the effects of the shell thickness, stiffness of material and the friction between two contacting surfaces in the contact calculation scheme, appropriate penalty parameters are defined to ensure smooth engagement of rollers with sprockets. A maximum search frequency, i.e., one search per time-step, is selected to ensure enough analysis accuracy, in spite of that it requires longer computation time.

Modeling of the power supply and power consumption is one of the most difficult aspects in analysis of dynamic systems. Since our numerical simulation is limited to the case of the chain-sprocket system running at a constant speed, a fixed rotational velocity of $120.74 \mathrm{rad} / \mathrm{s}$ is applied on the driving sprocket, which represents its rotation speed of 1153rpm. This rotational speed of driving sprocket is corresponding to a motorcycle speed of $50 \mathrm{~km} / \mathrm{h}$ and imposed on the center of the sprocket by the rotating $(\mathrm{z})$ - angular velocity boundary condition shown in Fig. 2 . In the initial 5 mini-seconds, the velocity is increased linearly from 0 to its maximum $120.74 \mathrm{rad} / \mathrm{s}$; after that this rotational velocity has been fixed at $120.74 \mathrm{rad} / \mathrm{s}$.

Meanwhile a constant resisting torque is applied on the driven sprocket representing a driven torque of $150 \mathrm{Nm}$. This driven torque is imposed on a spring element located at the sprocket's center point by the moment-resistance curve given in Fig. 3. The specially created spring element is a two-node one-dimensional element. One node of it is at the origin of local coordinate frame. The resisting torque is imposed at this node. The other node is at the local axis (s) of which the orientation is coincident with the rotating axis of the driven sprocket. Similar to imposing the velocity condition on the center of driving sprocket, the resisting torque imposed on the center of driven sprocket is linearly increased at first $0.03 \mathrm{rad}$ from 0 to its constant value, $150 \mathrm{Nm}$. The boundary condition of resisting torque, also the velocity boundary condition, is defined in such a way, i.e., linearly increased to its constant value, that the explicit solutions come to a steady condition as early as possible. Since explicit FE code will be employed 


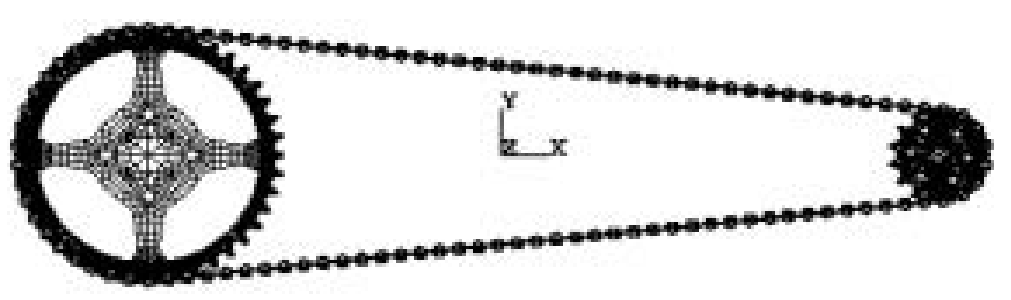

Fig. 4. The simple FE model of the chain drive.

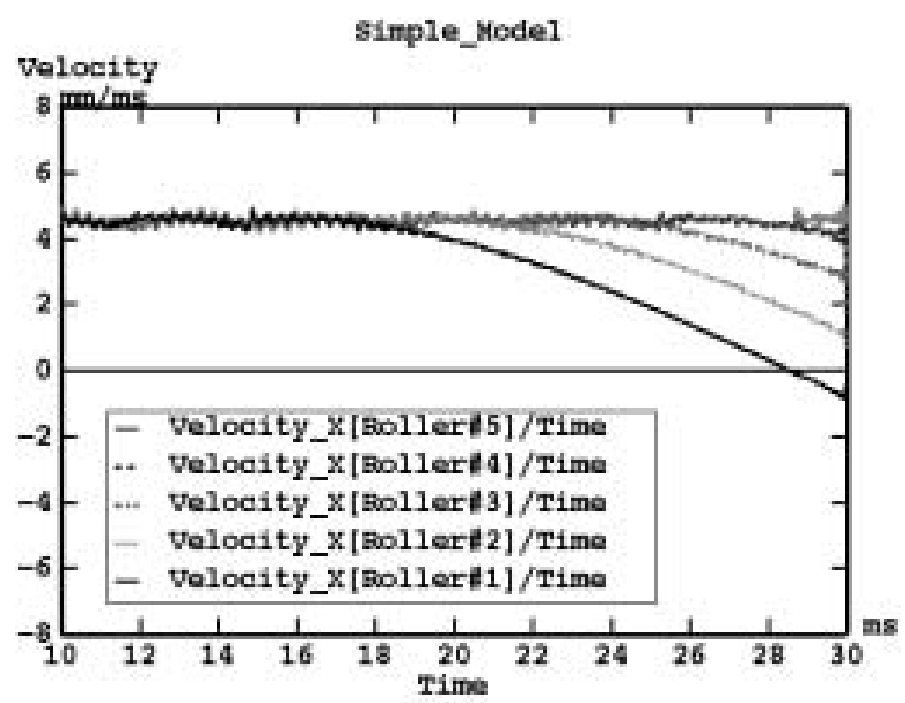

(a) in chain-span direction

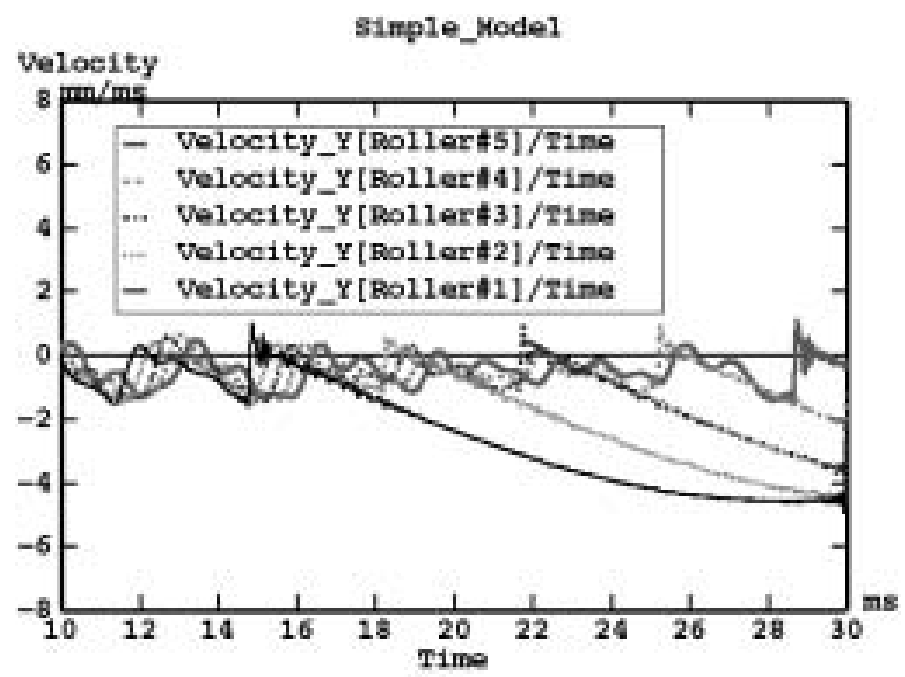

(b) in normal direction to chain span

Fig. 5. Velocity response of five rollers engaging successively with driving sprocket: simple model.

to solve the model, the behavior predicted depends very much on the initial conditions assumed at the start of the computation.

In the so-called "simple-model" (see Fig. 4), the chain strand is modeled as a series of lumped cylinders connected 


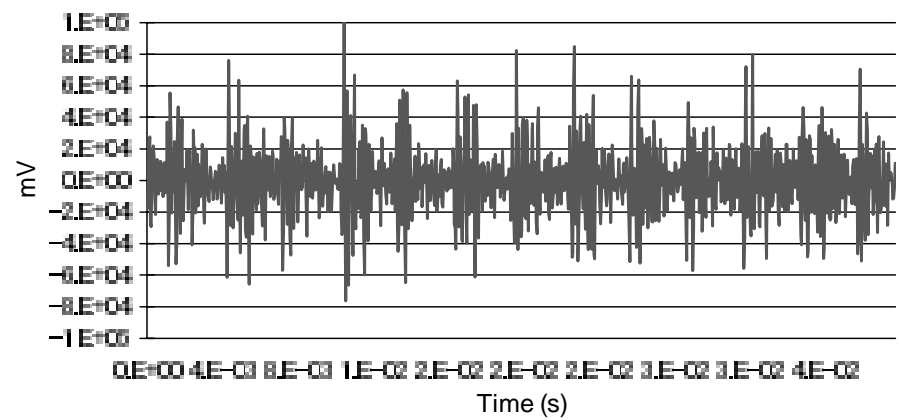

Fig. 6. A measured sound pressure of noise emitted from the simulated chain drive.

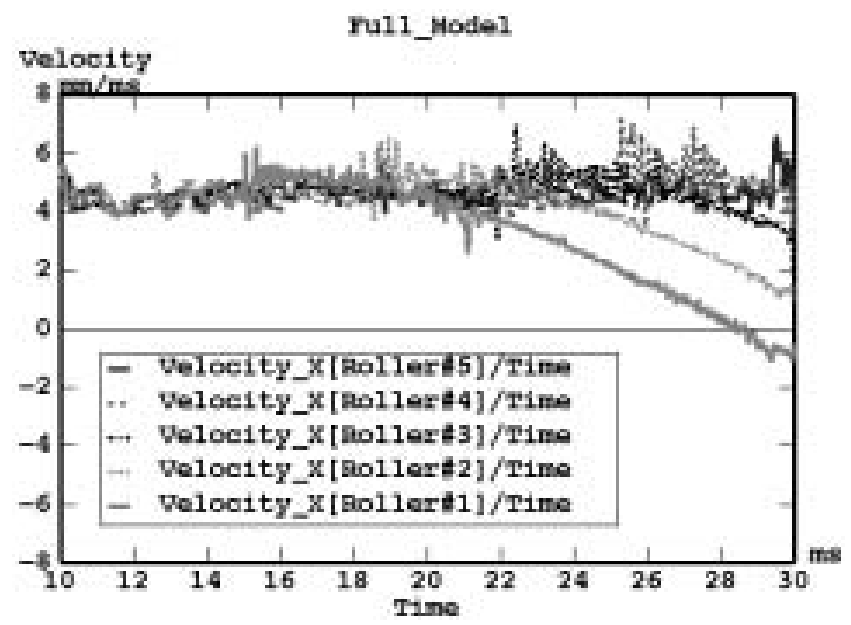

(a) in the direction of chain-span

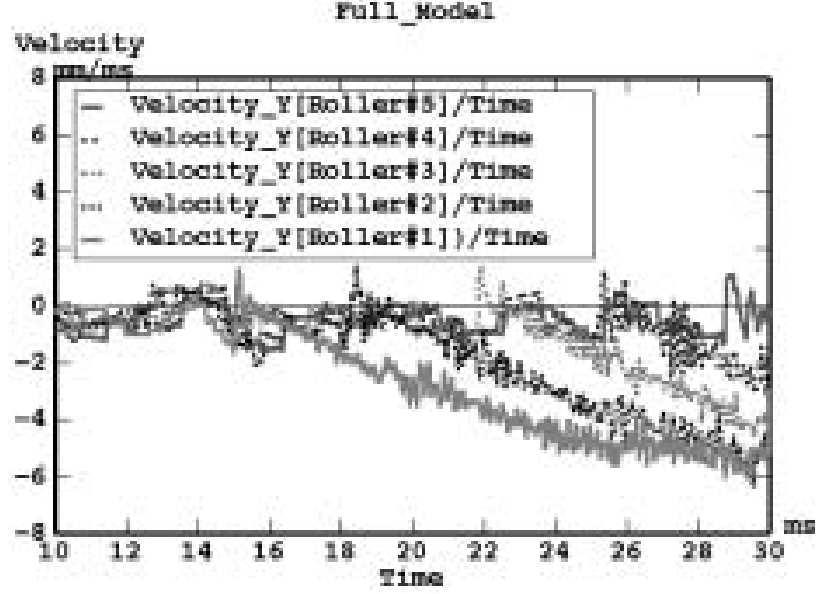

(b) in the normal direction to chain span

Fig. 7. Velocity response of five rollers engaging successively with driving sprocket: full model.

by elastic bars of constant axial stiffness, as assumed usually in nearly all theoretical analyses of chain drive dynamics. In FE analysis, this can be achieved by using "nodal constraint" to restraint the center of gravity (COG) of the lumped cylinders with correspondent ends of the elastic bars representing the chain side plates in the same motion in three translational degree-of-freedoms. Both the pin and bush are modeled as "added masses" attached on the 


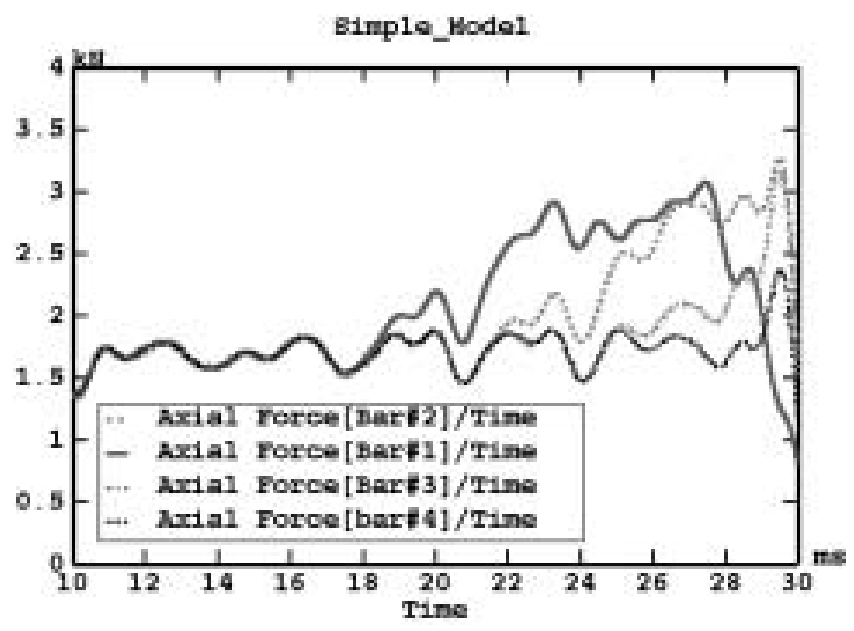

Fig. 8. Simulated axial forces of connecting bars in simple model.

COG of lumped cylinder for modeling the roller assembly. Under this nodal constraint condition, the mechanical clearance and also the relative motion among the three components are neglected explicitly. The uniform bars are used to substitute for the section-varying side plates modeled in the previous "full-model". Other finite element entities, such as boundary and loading conditions, and contact interfaces, are specified being identical with those defined in the full model. In this simple model, since the motion of the pin, bush and roller is restrained for each roller assembly, thus there are no contact interfaces between roller-bush and bush-pin, and solving this model needs a much less computation time than the full model.

PAM-Crash ${ }^{\mathrm{TM}}$, a commercial software code for explicit finite element analysis of nonlinear dynamic problems is employed to solve above two models respectively. The dynamic behaviour of both rollers and sprockets in time domain under specified loading and boundary conditions are therefore numerically simulated. The termination time input for one dynamic run is as long as $30 \mathrm{~ms}$, about 8 times the time $(3.472 \mathrm{~ms})$ for a roller to move in one pitch distance $(15.875 \mathrm{~mm})$ when the rotation speed of driving sprocket is $1153 \mathrm{rpm}$. Selected nodes on the rollers and interested locations of the two sprockets are specified to output the displacements, velocities and accelerations of roller and sprocket surfaces. The results from the software code include both a visualisation of the system behaviour and a data file with numerical results in time-domain.

\section{Numerical solutions and comparison}

The computation time required to solve a explicit finite element model depends mainly on the smallest time step for time integration which is determined by the wave propagation speed in the material and the smallest element mesh dimension. The CPU cost per time step is further related to the number of elements with some allowance for the contact surfaces. Table 3 compares the computation time used for solving each of simple and full models where the CPU time for solving the full model is nearly 164 times that for solving the simple model. This is because the section-varying side plates of each chain link are modelled in the simple model as uniform elastic bars, and the pin and bush are treated as added masses. The number of the elements and associate degree-of-freedom of motion is therefore much less than that of the full model. Furthermore, since no contact interface is required to be specified between each contact pair of roller-bush and bush-pin, the CPU time required for the contact search of the simple model is largely reduced. So comparatively, using the simple model to simulate the dynamic behaviour of a roller chain can save a large amount of computation time.

The excitation that causes the vibration of both chain spans and sprockets is very complex. However, the dynamic load due to polygonal action and the impact between rollers and the sprocket (driving) caused by the relative velocity as the roller seats to the sprocket tooth are two dominant sources of the excitation. Under these excitations, the vibration response of the engaging roller behaves in a complex manner. Figure 5 depicts the solution of velocity 


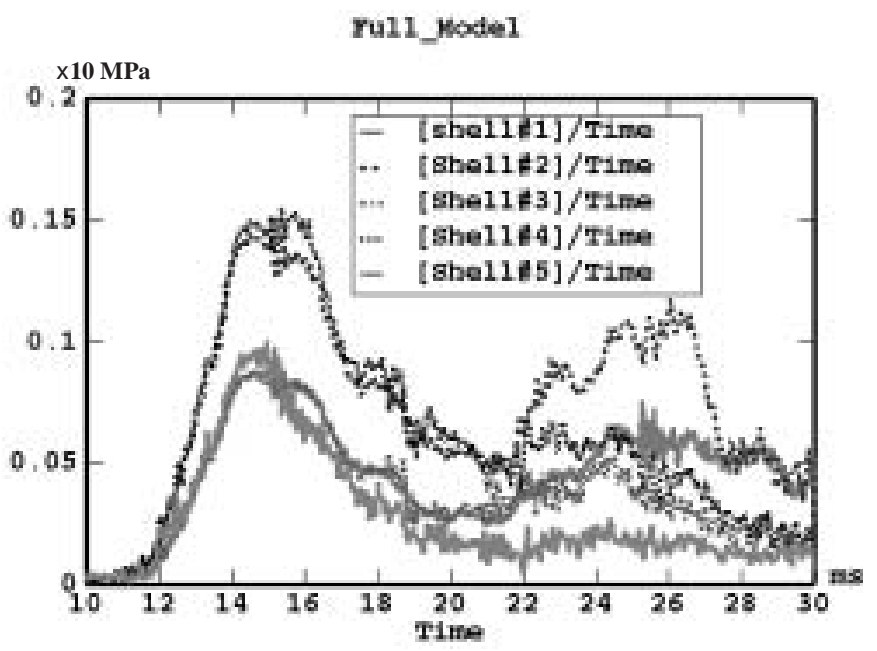

(a) about local first principal axis

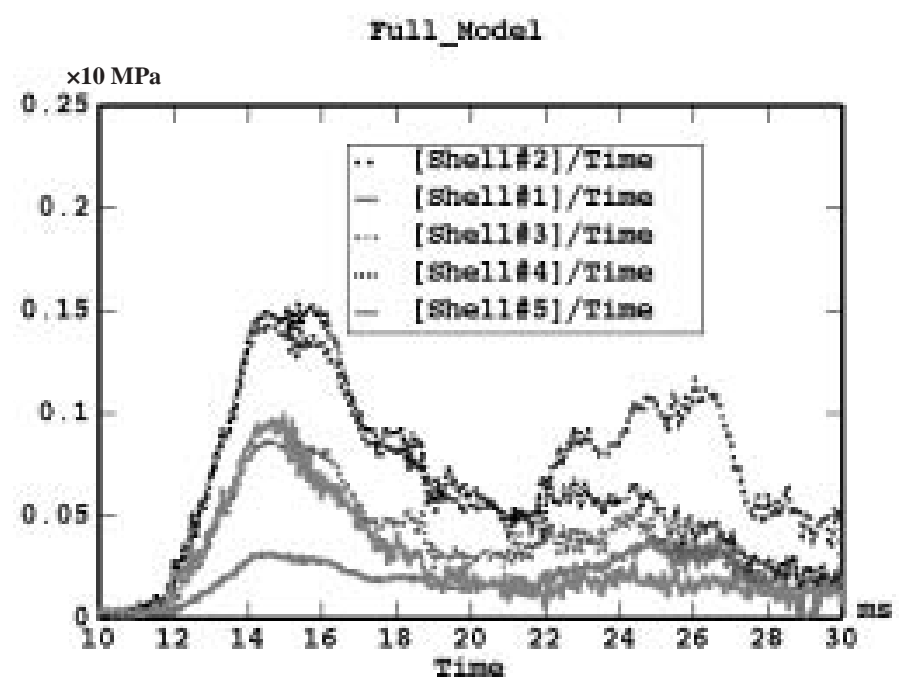

(b) about local second principal axis

Fig. 9. Stress of shell elements in side connecting plates.

response of five chain rollers engaged successively with driving sprocket teeth using the simple model. Since the motions in three translational degree-of-freedoms are restrained, the vibration response of the roller, bush and pin of one roller assembly do not behave any difference. The velocity of the node located at the geometry centre of the roller assembly represents that of the roller-bush-pin assembly. It can be easily seen that the velocity of the moving roller changes significantly in its impact direction (normal to tight chain span) when it seats on the sprocket tooth. This instant velocity change has been explained in many publications, e.g., in [10,17], and is due to the velocity direction changing of the moving roller before and after it seats on the sprocket tooth. More apparently, the vibration responses in each of two directions are nearly the same for all engaging rollers. This is coincident with the dynamic behaviour of chain drives revealed by many existing analytical studies.

Note that "Roller \#1-Roller \#5" depicted in Fig. 5 don't represent the first 5 roller pick-ups from starting of the computation. Actually because of two specific boundary conditions, one is the rotational speed at the center of driving sprocket and the other is the resisting torque at the driven sprocket as described previously, the results come to the steady state just after the calculation proceeds for about $8 \mathrm{~ms}$. In the post-processing, all the results during the first $10 \mathrm{~ms}$ of termination time with transient effects are taken away from the data file. Therefore, "Roller \#1 Roller 
$88.7 \mathrm{~dB}$

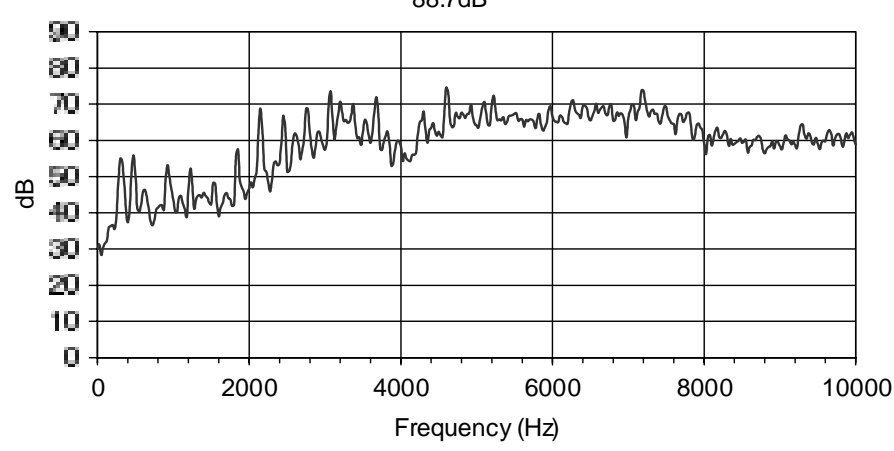

Fig. 10. Predicted noise spectrum using FE simulation Results.

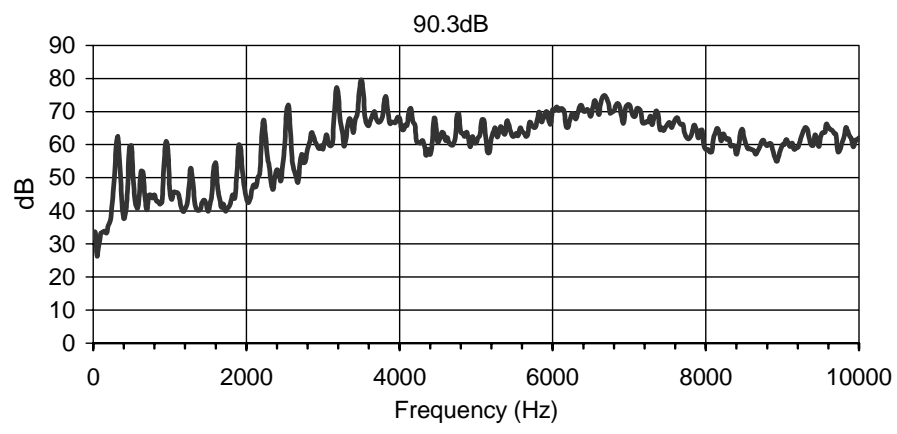

Fig. 11. Spectrum of the measured noise shown in Fig. 6.

\#5" in the figure represent the first 5 rollers successively engaging with the driving sprocket after the calculation proceeds for $10 \mathrm{~ms}$.

Figure 6 shows the sound pressure time-history of the noise measured on the chain drive for a motorcycle in a recent noise measurement [20]. The measurement was carried out in a small semi-anachoic room and the measuring microphone locates in the chain-sprocket plan and $0.4 \mathrm{~m}$ away from the engaging point of rollers with driving sprocket. The figure clearly illustrates that, despite a clear periodic component seen in the time history curve (the period coincides with the pitch time), the sound emission due to one roller/sprocket engagement is obviously different from one by one. Some roller/sprocket impacts cause higher noise emission while the others bring the chain-sprocket system lower noise emission. Theoretically, the noise emission from a chain-sprocket system is attributable to the vibration of both engaging rollers and the sprockets under the excitations due to the system polygon action and especially the roller-sprocket impacts. From the measured sound pressure in the time-domain, it can be derived that the vibration response of the engaging roller is varying from one by one. Apparently, existing analytical methods for dynamic behaviour of chain drives cannot appropriately explain this variance.

Owing to the gaps between roller-bush and bush-pin which induce the difference in the vibration response of the three components of one roller assembly from each other, the full model of chain-sprocket system should be solved. As described above, in the full model, all the mechanical elements involved in the engagement of rollers with sprockets are modelled in full geometry. The relative motions among the roller, bush and pin in all six degree-of freedoms are allowed.

The vibration velocities of the nodes on the roller surfaces solved using the full model are given in Fig. 7. Figure 7(a) shows the velocity responses in normal direction to the chain span while depicted in Fig. 7(b) are the results in the tangent direction of the chain span. Apparently, taking into account the interactions between roller-bush, bush-pin, the calculated dynamic response of the roller when it seats on the sprocket is more complicated than that simulated by using the simple model where the roller assembly is modelled as a lumped cylinder. From the results shown in Fig. 7, it can be easily seen that there exists a big difference in the vibration response between the rollers 


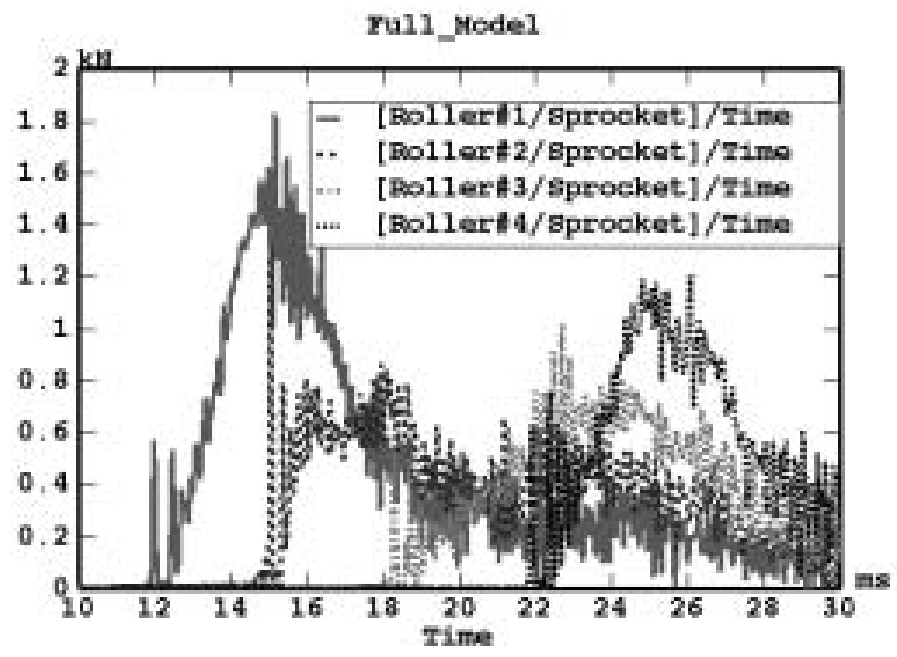

Fig. 12. Simulated contact force between rollers and driving sprocket using full model.

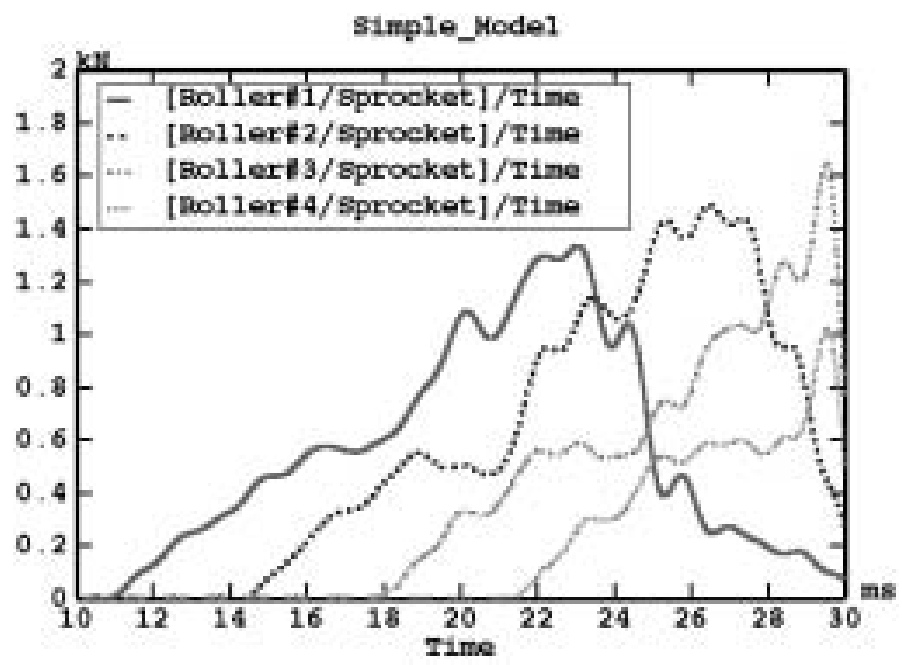

Fig. 13. Simulated contact force between rollers and driving sprocket using simple model.

when they are engaging with driving sprocket successively. This should be attributed to complicated interaction between all inter-contact components. Also the force transmission between two neighbour roller assembly via side-plates should be responsible for the variance in the vibration response among the successively engaging rollers. The simple model cannot predict this variance of vibration response because the connecting side-plates in the model are modelled as uniform bars which transmit the force in their axial direction. Figure 8 shows the simulated axial forces of five successive connecting bars using the simple model. Actually, owing to the friction between contacting components and their elasticity, the side-plates behave more like elastic beams bearing both extension and bending in the chain-sprocket plane. Figure 9 shows the stress solutions of five shell elements about their local first and second principal axis corresponding respectively to chain-span direction and normal direction to chain-span. These shell elements are correspondingly on five side plates of one chain span side which connect six roller assemblies successively engaging with driving sprocket.

A practical approach is developed recently to predict the chain drive noise emission. Since the details of the approach have been presented in earlier work [18], only a summary of it is presented here.

This approach is basically a two-step work. Firstly, an acoustical model relating the dynamic response of the 
rollers and its induced sound pressure is developed based on the fact that the acoustic field is mainly created by oscillating rigid cylindrical rollers. Secondly, explicit finite element techniques and numerical software codes are employed to model and simulate the acceleration response of each chain roller, such as what is presented in this paper. These data are necessary for noise prediction of a chain drive under varying operation conditions and different sprocket configurations.

Using the vibration response information obtained through solving above full model, the developed program in FORTRAN language calculates the sound pressure time-histories at a total of twelve observing points distributed uniformly on a semi-cylindrical hypothetical surface enveloping the chain-sprocket drive. Through FFT, the timehistory of predicted sound pressure might be transferred into the data in frequency-domain. It is illustrated that the biggest discrepancy is $1.9 \mathrm{~dB}$ between the predicted sound pressure levels at observing points and the measurements in a semi-anachoic room. Figure 10 shows the predicted spectrum of the sound pressure at same observing point as that for the measurement of sound pressure given in Fig. 6, of which the frequency spectrum is shown in Fig. 11. It can be observed that two spectrum are in good agreement.

The dynamic load between roller-sprocket due to the impact is also an important factor considered in the chain drive design. Liu et al. [15] recently found that there is a direct relationship between the chain-sprocket meshing impulsive loads and the near field sound pressure levels. Figure 12 shows the roller-sprocket contact forces of five rollers successively engaged with the driving sprocket calculated using the full model. It is illustrated again that the impulsive roller-sprocket contact force is varying in a quite large range. For example, the maximum contact force is as large as $1.82 \mathrm{kN}$ between roller \#2 and sprocket, but between roller \#4 and sprocket it is about $1.05 \mathrm{kN}$, nearly $40 \%$ less than the largest. The simple model results show that there do exists certain variance in the impulsive contact force between the roller-tooth pairs, see Fig. 13, but this variance is so small as comparing with the full model results. Also the obtained profile of the contact force time-history is totally different using the simple and full model respectively.

\section{Conclusion}

Using a simple model as adopted in nearly all previous analytical studies on the dynamic behavior of chain drives, i.e., where the roller-bush-pin assemblies are modeled as lumped cylinders and the section-varying side-plates are simplified to uniform bars only transmitting force in their axial direction, the variance of the sound pressure of noise emission from a roller chain drive may not be appropriately explained. The actual vibration response of the roller engaging with sprocket is more complex than that predicted by using above simple model. Both numerical FE dynamic simulation and physical measurement on the noise emission from a chain drive system verify that owing to the interactions between roller-bush and bush-pin, and also the elastic beam-like behavior of the connecting side-plates for chain links, the vibration response and roller-sprocket contact force is not identical for all engaging rollers but different from one by one in a quite large extent. In order to achieve a comprehensive understanding in the dynamic behavior of chain drive and a reliable prediction of its noise emission, the full model taking into account the physical details of the system should be employed, although it would be in the price of a much longer computation time.

\section{References}

[1] M.R. Naji and K.M. Marshek, Analysis of sprocket load distribution, Mech. Mach. Theory 18(5) (1983), 349-356.

[2] M.R. Naji and K.M. Marshek, Experimental determination of the roller chain load distribution, J. Mech. Transm. Autom. Des. Trans. ASME 105 (1983), 331-338.

[3] J.C. Conwell and G.E. Johnson, Design, construction and instrumentation of a machine to measure tension and impact forces in roller chain drives, Mech. Mach. Theory 31(4) (1996), 525-531.

[4] J.C. Conwell and G.E. Johnson, Experimental investigation of link tension and rollor-sprocket impact in roller chain drives, Mech. Mach. Theory 31(4) (1996), 525-531.

[5] S.R. Turnbull and J.N. Fawcett, An approximate kinematic analysis of the roller chain drive, Proc. 4th World Cong. Theory Mach. Mech. ASME (1975), 907-911.

[6] C.-K. Chen and F. Freudenstein, Toward a more exact kinematics of roller chain drives, J. Mech. Transm. Autom. Des. Trans. ASME 110 (1988), 269-275 
[7] R.A. Sack, Transverse oscillations in travelling strings, British J. Applied Physics 5 (1954), 224-226.

[8] S. Mahalingam, Transverse vibrations of power transmission chains, British J. Applied Physics 8 (1957), $145-148$.

[9] S.R. Turnbull and J.N. Fawcett, Dynamic behaviour of roller chain drives, Instn. Mech. Engrs. (1973), 29-35.

[10] M. Chew, Inertia effects of a roller chain on impact intensity, J. Mech. Transm. Autom. Des. Trans. ASME 107 (1985), 123-130.

[11] J.W. Fawcett and S.W. Nicol, A theoretical investigation of the vibration of roller chain drives, Proc. 5th World Cong. Theory Mach. Mech. (1979), 1482-1485.

[12] M.S. Kim and G.E. Johnson, A general, multi-body dynamic model to predict the behaviour of roller chain drives at moderate and high speeds, ASME DE-Vol.65-1, Advances in Design Automation 1 (1993), 257-268.

[13] K.M. Wang, On the stability of chain drive systems under periodic sprocket oscillations, ASME J. Vibrations \& Acoustics 114 (1992), $119-126$.

[14] K.M. Wang, S.P. Liu, S.I. Hayek and F.H.K. Chen, On the impact intensity of vibrating axially moving roller chains, ASME J. Vibrations \& Acoustics 114 (1992), 397-343.

[15] S.P. Liu, K.M. Wang, S.I. Hayek and M.W. Trethewey, A global-local integrated study of roller chain meshing dynamics, J. Sound \& Vibration 203(1) (1997), 41-62.

[16] W. Choi and G.E. Johnson, Vibration of roller chain drives at low, medium and high operating speeds, ASME DE-Vol.63, Vibrations of Mech. Systems \& History of Mech. Design (1993), 29-40.

[17] N.M. Veilos and F. Freudenstein, On the dynamic analysis of roller chain drives, ASME DE-Vol.46, Mechanical Design and Synthesis (1992), 431-450

[18] H. Zheng, Y.Y. Wang, G.R. Liu, K.Y. Lam, K.P. Quek, T. Ito and Y. Noguchi, Efficient modelling and prediction of meshing noise from chain drives, Journal of Sound \& Vibration 245(1) (2001), 133-150.

[19] PAM-Crash User's Training Manual, Oct. 1996.

[20] H. Zheng, K.P. Quek, Y.Y. Wang, G.R. Liu, Y. Noguchi and K.Y. Lam, An investigation of meshing noise of roller chain drives for power transmission of motorcycles, Noise Control Engineering Journal 50(1) (2000), 5-11. 

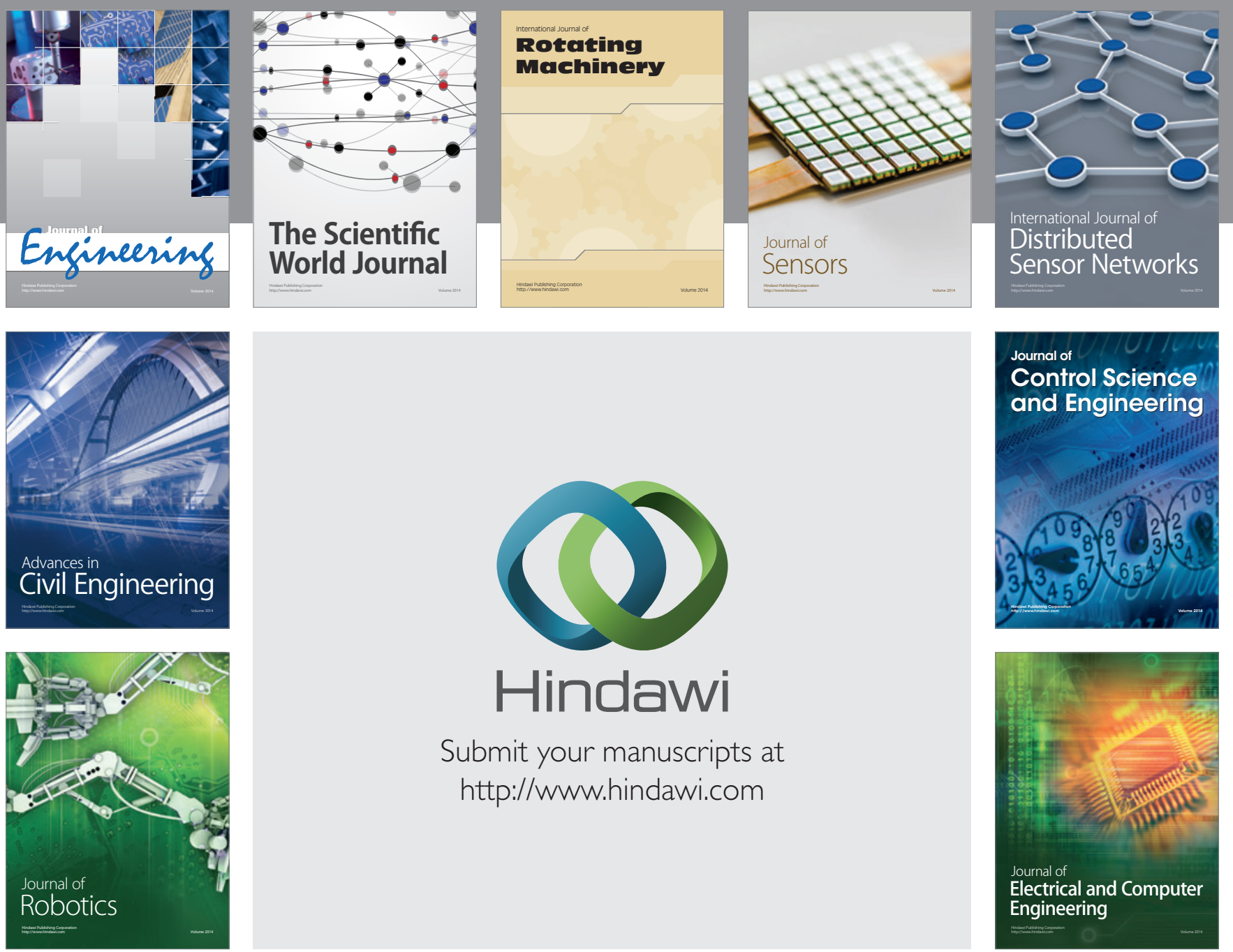

Submit your manuscripts at

http://www.hindawi.com
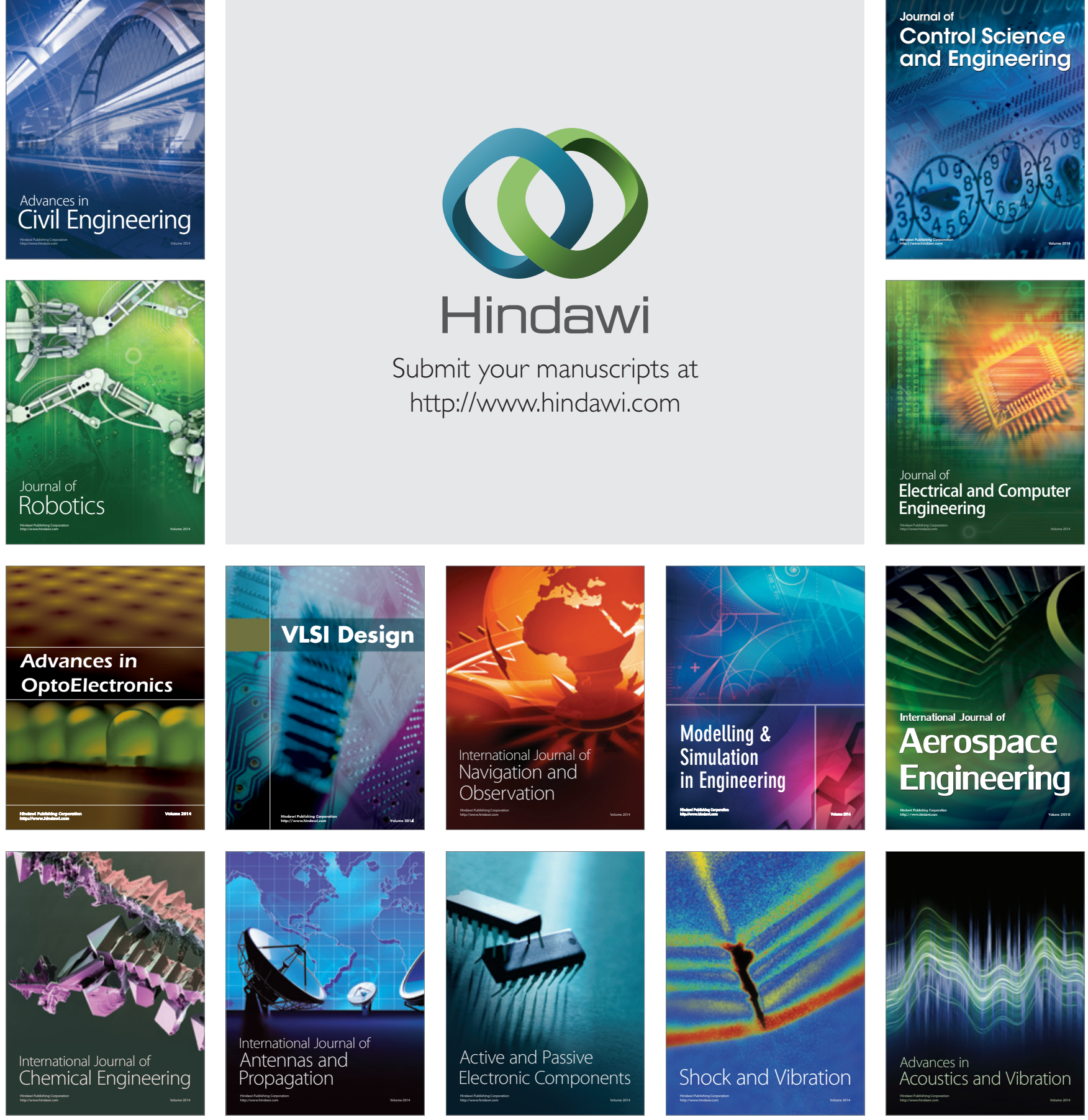